\title{
Correction to: Validation of the Spanish Version of Fear of COVID-19 Scale: its Association with Acute Stress and Coping
}

\section{J. A. Piqueras ${ }^{1,2} \cdot$ M. Gomez-Gomez ${ }^{3}$ J. C. Marzo ${ }^{1,2} \cdot$ P. Gomez-Mir ${ }^{4}$ R. Falco ${ }^{1,2}$. B. Valenzuela ${ }^{5}$. PSICORECUR-SOS COVID-19 study group}

(c) Springer Science+Business Media, LLC, part of Springer Nature 2021

\section{Correction to: International Journal of Mental Health and Addiction https://doi.org/10.1007/s11469-021-00615-x}

The last seven five words of this article's title ("its Association with Acute Stress and Coping") were repeated in the article as originally published.

The original article has been corrected.

Publisher's Note Springer Nature remains neutral with regard to jurisdictional claims in published maps and institutional affiliations.

The original article can be found online at https://doi.org/10.1007/s11469-021-00615-X

\section{J. A. Piqueras}

jpiqueras@umh.es

1 Department of Health Psychology, Faculty of Social and Health Sciences, Miguel Hernandez University, Avda. de la Universidad, s/n. Edf. Altamira, 03202 Elche, Alicante, Spain

2 Center for Applied Psychology, Miguel Hernandez University, Avda. de la Universidad, s/n. Edf. Altamira, 03202 Elche, Alicante, Spain

3 Centro Psytel-Psicología y Sexología and Centro Arela Logopedia, Madrid, Spain

4 Centro Psicología y Salu and Universidad Nacional de Educación a Distancia, Madrid, Spain

5 Grupo Profesional Psicológicamente, Praxis Psicología Integral, and Centro Integral de Desarrollo Infantil (CIDI Children), Santo Domingo, Dominican Republic 